\title{
Diverse Mechanisms of Allergen Specific Immunotherapy
}

\author{
Lacin Cevhertas ${ }^{1}$, Mübeccel Akdis ${ }^{2}$ \\ ${ }^{1}$ Department of Immunology, Institute of Health Sciences, \\ Bursa Uludag University, Bursa, Turkey \\ ${ }^{2}$ Swiss Institute of Allergy and Asthma Research (SIAF), \\ University of Zurich, Herman-Burchard-Strasse 9, \\ CH-7265 Davos Wolfgang, Switzerland
}

\begin{abstract}
Allergen immunotherapy (AIT) is widely used to establish a tolerant immune response and it is currently the only disease modifying treatment. There are different routes to administer the allergen, including subcutaneous, sublingual, intralymphatic, epicutaneous, intradermal, and oral and local nasal allergen immunotherapy. Although the optimal administration route depends on the type of allergen, some patients remain unresponsive and so it is important to predict the outcome before and during treatment. Therefore, there is a need to identify candidate prognostic markers for allergen immunotherapy. Herein, we discuss the recent literature on the molecular mechanisms of AIT.
\end{abstract}

Key words: allergen immunotherapy (AIT), allergen, subcutaneous, sublingual, intralymphatic, epicutaneous, intradermal, oral, nasal, prognostic markers

Correspondence author: Mübeccel Akdis, MD, PhD, Swiss Institute of Allergy and Asthma Research (SIAF), Herman-BurchardStrasse 9, CH-7265 Davos Wolfgang, Switzerland; E-mail: akdism@siaf.uzh.ch

ORCID ID: 0000-0003-2113-1870

For citation: Lacin Cevhertas, Mübeccel Akdis. (2019). Diverse Mechanisms of Allergen Specific Immunotherapy. RUDN Journal of Medicine, 23 (3), 233-249. DOI: 10.22363/2313-0245-2019-23-3-233-249.

Для цитирования: Лацин Цевертас, Акдис Мубацел. Разнообразие механизмов аллерген-специфической иммунотерапии // Вестник Российского университета дружбы народов. Серия: Медицина. 2019. Т. 23. o 3. С. 233 -249. DOI: $10.22363 / 2313-0245-2019-23-3-233-249$.

\section{Abbreviations}

Th, T helper

Ig, immunoglobulin

DCs, dendritic cells

VEGFa, vascular endothelial growth factor A

SCIT, subcutaneous allergen immunotherapy

OIT, Oral immunotherapy

SLIT, Sublingual allergen immunotherapy

SLIT-tablet, Sublingual immunotherapy tablet
HDM, house dust mite

ILIT, Intralymphatic immunotherapy

EPIT, Epicutaneous immunotherapy

APCs, antigen-presenting cells

IDIT, intradermal immunotherapy

poly lactic-co-glycolic acid, PLGA

LNIT, Local nasal immunotherapy

Der $\mathrm{p}$, Dermatophagoides pteronyssinus

IL, interleukin

Tregs, regulatory $\mathrm{T}$ cells 
Bregs, regulatory B cells

ILCs, innate lymphoid cells

TGF, transforming growth factor

nTregs, natural Tregs

$\mathrm{H} 2 \mathrm{R}$, histamine type 2 receptor

$\mathrm{nNO}$, nasal nitric oxide

$\mathrm{Tfh}$, follicular helper $\mathrm{T}$

TCR, T cell receptor

CRTH2, prostaglandin $\mathrm{D} 2$ receptor

CCR, C-C chemokine receptor

ILC1s, Group 1 ILCs

ILC2s, group 2 ILCs

ILC3s, group 3 ILCs

$\mathrm{ROR} \gamma \mathrm{t}$, retinoic acid-related orphan receptor gamma $\mathrm{t}$

cDCs, classical/conventional dendritic cells

LP, lamina propria

MesLNs, mesenchymal lymph nodes

CD-Sens, allergen threshold sensitivity

DAO, diamine oxidase

tIgE, total IgE

sIgG4, allergen-specific IgG4

IgE-FAB, IgE-facilitated allergen binding to B cells

ISAC, Immuno-solid-phase allergen chip

DCregs, regulatory dendritic cells

sIgG4, allergen-specific IgG4

ISAC, Immuno-solid-phase allergen chip

$\operatorname{Tr} 1, \operatorname{Tr} 1$ type regulatory

\section{Key Messages}

- Monitoring the alteration in T cells and regulatory B cells during IT treatment may predict the outcome of AIT.

- Regulatory B cells are capable of inducing tolerance in patients who respond to AIT through their IL-10+IL1RA, as well as their IgG4 products which capture the allergen before it reaches IgE.

- As a consequence of SLIT, OIT, and EPIT are epigenetic alterations in the FoxP3 promoter region in Tregs which is important to prolonged production of Tregs.

- Ratios of IgG4, IgA, and IgA2 to IgE might be functional to assess the benefit and clinical response to AIT.

\section{Introduction}

Allergies develop due to the immune response to discrete environmental protein antigens, called allergens [1]. The first step in development is known as the sensitization phase. Subsequent activation of dendritic cells (DCs) with the allergen lead to the expansion of allergen-specific T helper (Th) 2 cells. These clones can induce Ig (immunoglobulin) E isotype switching in B cells and differentiation into IgEsecreting plasma cells. The IgE then binds to the highaffinity FceRI on basophils and mast cells. Once the allergen crosslinks the $\mathrm{IgE}$ antibodies bound to these receptor, it elicits a type I hypersensitivity reaction triggering the degranulation and release of various synthesized mediators such as histamine, leukotrienes, heparin, some proteases in addition to TNF- $\alpha$ and vascular endothelial growth factor A (VEGFa) (Figure 1) [1].

Since the discovery of the molecular structures of allergens it has become possible to produce recombinant and synthetic allergens and use them in allergen-specific immunotherapy (AIT) to induce a protective immune response [2]. AIT is widely used for establishing a tolerant immune response as well as maintaining a long-lasting effect, even if the patient displays inconsistent treatment compliance. Furthermore, AIT is a cost-saving method when compared to anti-cytokine antibodies and is able to decrease the usage of symptomatic drug treatment [3]. Even though AIT is the only disease modifying treatment, this therapy is limited by its efficacy, safety, length, patient adherence to treatment [4], and importantly, not every patient responds to treatment. In the interest of determining the effects of AIT on developing immune tolerance to allergens, routine laboratory tests and biomarkers must be developed $[1,5]$, and so there is a need to improve our understanding of the immunological mechanisms involved.

In this review, we focus on the current literature on the various mechanisms of immunotherapy and potential biomarkers for monitoring clinical and immunological response to AIT for stratification of patients.

\section{General Methods and Novel Approaches of Administration}

Various guidelines for AIT are available but in a methodological manner they are heterogeneous. Up to now, subcutaneous allergen immunotherapy (SCIT) has been the major administration route of AIT. In this section, we define and discuss SCIT and other promising AIT routes, including epicutaneous, sublingual, intradermal, intralymphatic, oral, and nasal $[6,7]$. 


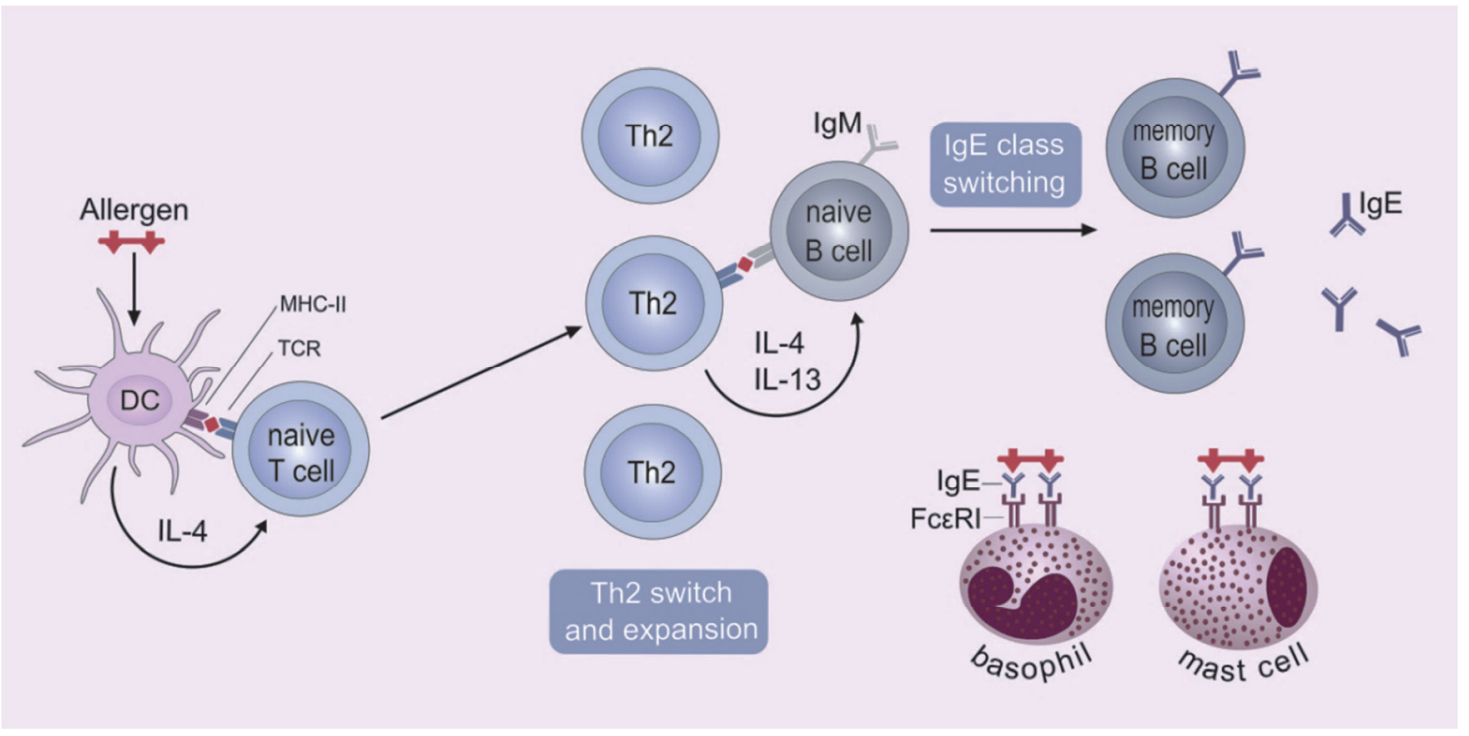

Fig. 1. Mechanisms of allergic immune response

Рис. 1. Механизм иммунного ответа на аллергены

In SCIT the allergens can be either aqueous or physically-adsorbed (depot) extracts, or chemically modified allergens (allergoids) as depot formulations [8]. The efficacy of SCIT has been demonstrated with beevenom, ragweed pollen, dust mite, grass pollens, cat and dog dander, and the dosing regimen has been optimized [9]. Moreover, it is an efficacious treatment for adults and children who have allergic rhinitis (AR) with or without asthma [8], and in AR patients with or without conjunctivitis [10]. In addition, the standard duration of treatment is between $3-5$ years with respect to prospective studies of SCIT with grass pollen and house dust mite (HDM) extract in AR and asthmatic patients [11]. Although it is the most common IT route, the administration of SCIT remains limited due to the frequent injections required for a period of at least 3 years [9]. Adverse reactions mostly appear within 30 minutes after injection and are usually observed as local reactions (injection site redness and swelling) [12]. It is also worth to point out that current SCIT challenges include allergen heterogeneity, dosage optimization and duration of treatment.

Sublingual allergen immunotherapy (SLIT) comprises sublingual (oral) administration of a certain amount of allergen extract which causes the allergy [13]. However, biodistribution studies have shown the lack of systemic absorption of allergen through the oral mucosa after sublingual administration. Hence, the clinical effect should arise from the local interaction of the allergen with the mucosal immune system. Different formulations of allergens have been developed as alternatives to SCIT, such as the sublingual immunotherapy tablet (SLIT-tablet). Particularly SLIT-tablets may be beneficial for children who are scared of injections and needles [14]. The SLIT-tablets have been developed for the treatment of grass pollen-induced AR and HDMinduced AR but the allergen content and dosing have not been standardized to date. The varied content among different products also affects the guidelines [15]. In addition, a limitation of SLIT tablet occurs from its ingredient which consists of only one antigen [14]. It has been recently demonstrated that pharmaceutical SLIT-tablet formulations are also important and affects the efficacy with which allergen has delivered from the dry state of the tablet into a soluble form [16]. SLIT has a good safety and tolerability profile compared to SCIT owing to the lack of systemic exposure to intact allergens and low frequency of systemic allergic reactions [14].

Oral immunotherapy (OIT) is an option for treatment of food allergy and has been broadly used to treat peanut, cow's milk, and egg allergy in clinical practice [7]. The food used in the study was 
prepared at low concentrations through a serial dilutions of food suspensions [17]. It has shown that low-dose OIT has the capability of achieving sustained unresponsiveness in children with peanut anaphylaxis by inducing immunological changes [18]. On the other hand, OIT can be given in an adult patient who has severe milk, peanut, or egg allergy under certain conditions. Even though OIT leads into desensitization it still remains unclear whether tolerance is persistent [19]. Long-term OIT in adults has a different efficacy and safety profile and requires further inspection, even though a similar risk and rate of allergic and anaphylactic events during build-up and maintenance phase has been demonstrated [20]. The most common side effect is itching, however, compared with other AIT administration route, OIT is prone to frequent and more severe adverse events, for instance, anaphylaxis, gastrointestinal side effects, and eosinophilic esophagitis $[19,21]$. Consequently, there is a large gap in studies related to OIT due to focusing mostly on peanut OIT which must be filled in immediately.

Intralymphatic immunotherapy (ILIT) is a direct intralymphatic injection of the antigen into lymph nodes, which improves patient adherence to AIT treatment by reducing the number of applications and length of treatment [6]. The major advantages of ILIT are the short duration of treatment and the administration of allergen extract at low doses. Clinical trials have shown that ILIT against grass pollen and bee venom is safe and efficient. It also has a reduced risk of systemic adverse effects, such as anaphylaxis that can have fatal consequences. This novel route of administration is promising but more clinical data is necessary to approve the routine use of ILIT [22].

Epicutaneous immunotherapy (EPIT) benefits from the skin's immune properties to regulate allergic responses. Hence it is one of the allergen-specific immunotherapy approaches currently being investigated for rhino-conjunctivitis and food allergies [23]. EPIT requires depositing the allergen onto a patch with a surrounding adhesive [24]. Two different epicutaneous delivery systems were developed for the purpose of improving allergen skin penetration [23, 25]. Tape stripping consists of physical removal of the epidermis corneal layers before allergen patch administration, which increases allergen passive diffusion through the epidermal layers. Allergen penetration creates a pro-inflammatory state which increases the interaction between the allergen and antigen-presenting cells (APCs). The hydration/occlusive system forms an occlusive chamber, which permits water to go up from the basal layer to the corneum stratum of the epidermidis. Thus, the allergen can reach the deep epidermis stratum and it is carried by Langerhans cells to local regional lymph nodes $[23,26]$. When compared to SCIT or OIT, application of allergen to intact skin is less invasive, without the need for injection or swallowing of an allergen [24]. EPIT is well tolerated, except that only mild skin irritation may occur at the patch site. Furthermore, EPIT shows a desensitization effect lower than OIT and SLIT and an outstanding safety profile [27].

Intradermal immunotherapy (IDIT) is a different AIT administration approach, which is based on allergen injection into the epidermis. A recent study focused on the potential of intradermal delivery of nanoparticle vaccines by using hollow microneedles. This study showed that nanoparticles coated with poly lactic-co-glycolic acid (PLGA) induced a stronger IgG2a response than mesoporous silica nanoparticles, gelatin nanoparticles and liposomes. Moreover, $\mathrm{CD} 8^{+}$and $\mathrm{CD} 4^{+} \mathrm{T}$ cell responses were highest when induced by OVA/poly(I:C)loaded liposomes [28]. In summary, a microneedle delivery method was suggested for the intradermal injection of nanoparticle vaccines. This novel antigen administration approach was tested in murine models [28]. However, it may induce tolerance more efficiently in human compared to other administration routes.

Local nasal immunotherapy (LNIT) involves the spraying of allergen extracts directly into the nasal cavity. These allergens can be natural or chemically modified and are provided in a soluble form. It seems that LNIT is effective for the treatment of allergic rhinitis [29]. However, the study with children has proved that LNIT frequently causes 
a local adverse reaction [30]. Novel techniques have been developed to reduce the number of persistent nasal reactions and ease the implementation. A recent Dermatophagoides pteronyssinus (Der p)-coated strip has been developed for self-application. Although there were no systemic adverse events, some patients had transient nasal symptoms during LNIT treatment but were controlled with oral prednisolone [29].

\section{An Overview of the Cellular and Molecular Mechanisms of AIT}

There are various factors which play different roles in developing an allergy. Western lifestyle or living without chronic infections with mycobacteria, helminths or Helicobacter in an environment causes increased Th2 cell immunity via loss of regulatory $\mathrm{T}$ cells (Tregs) or interleukin (IL)-10-producing regulatory B cells (Bregs) [31]. Dysregulation in Th2 immunity is seen with increased concentrations of allergen-specific immunoglobulin IgE caused by IgE-dependent degranulation of mast cells and basophils. Moreover, IL-4 secreting innate lymphoid cells (ILCs) and natural killer T cells are also involved in the further development of type 2 immune responses [32]. Each of these factors plays a part in allergic inflammation. AIT is relevant to all of these previously mentioned components. The aim of AIT is to re-establish immune tolerance to allergens (Figure 2). Different types of AIT may comprise various mechanisms. Recent findings are written below.

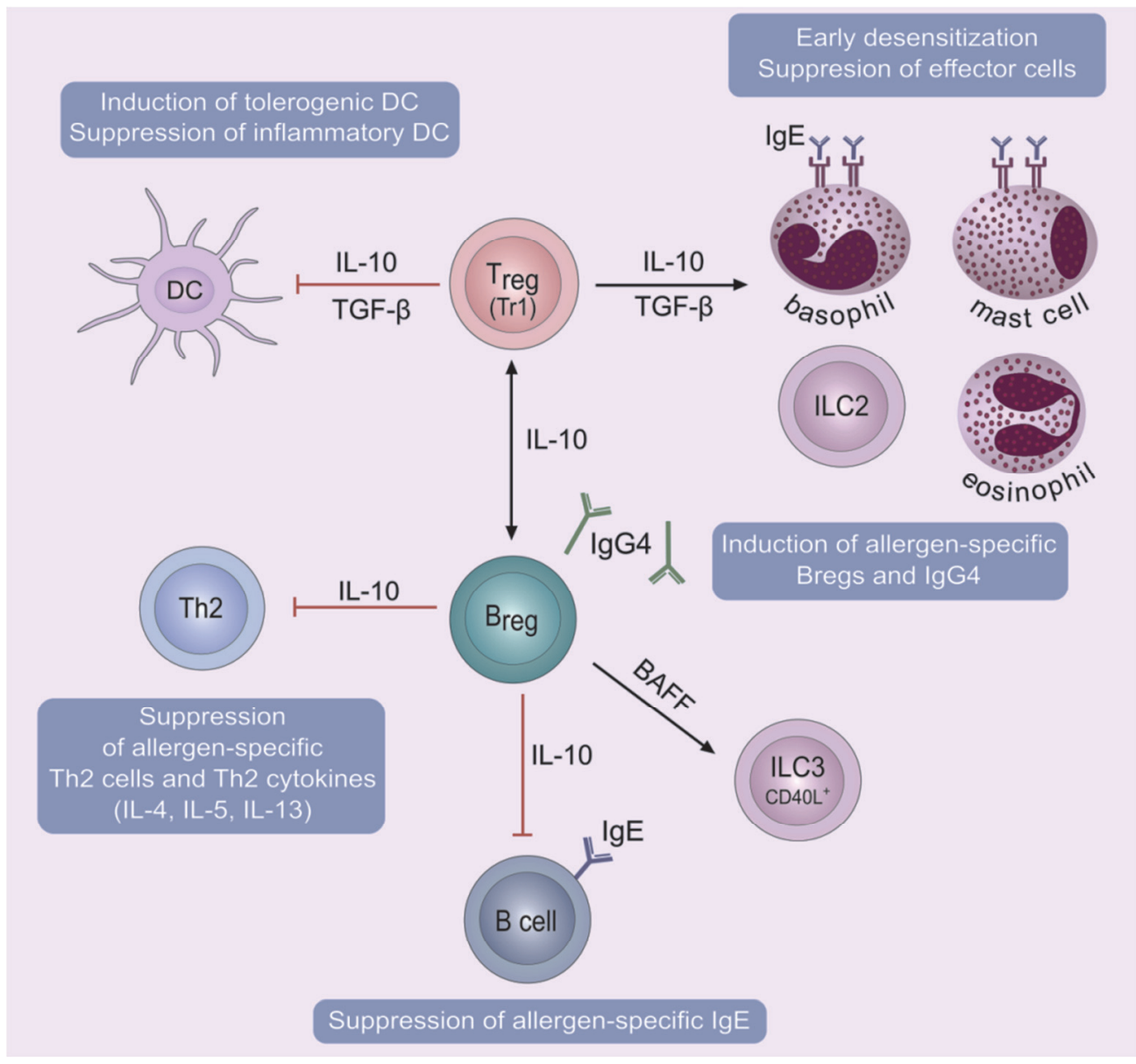

Fig. 2. Mechanisms of immune tolerance during AIT

Рис. 2. Механизм формирования иммунологической толерантности к аллергенам 


\section{SCIT Mechanisms}

It is well known that the essential mechanisms of SCIT involves the reestablishment of the peripheral $\mathrm{T}$ cell tolerance via inducing different types of Treg cells [33]. It has been demonstrated that IL-10-secreting $\operatorname{Tr} 1$ cell numbers were increased after 3 months and remained constant until 12 months in peripheral blood [34]. Similarly, a 2-year study with grass pollen SCIT showed increased numbers of IL-10+ Tregs in nasal mucosa [35]. In addition to Tregs, bee venom immunotherapy can also induce and maintain tolerance through IL-10-producing $B$ regulatory subsets in patients during bee venom immunotherapy [36]. In a recent study also demonstrated Der $\mathrm{p} 1$-specific B-cell and Breg cell responses over a 2-year period during AIT and suggests novel mechanisms of allergen tolerance, such as an increase in numbers of circulating allergen-specific memory B cells and IL-1RA production by Breg cells [37].

\section{SLIT Mechanisms}

After sublingually (oral) administration of a particular allergen, an antigen is presented to Tregs. They secrete IL-10 and transforming growth factor (TGF)-b which can induce the primary IgG4 subtype and IgA antibodies production by B cells. These antigen-specific IgG antibodies can block the allergic inflammation cascade outcome of antigen recognition by IgE. Furthermore, Tregs suppress IgE production via downregulating cytokine production in Th2 cells [13].

\section{ILIT Mechanisms}

In a novel approach with major cat allergen Feld1 has demonstrated that after intralymphatic immunotherapy with recombinant MAT-Feld1 in a human, a predominant subclass of IgG was observed as IgG4 instead of IgG, IgG2 and IgG3 [38]. $\mathrm{T}$ cell unresponsiveness to allergen identified by increased allergen-specific IL-10-producing FOXP3 positive Tregs [22].

\section{EPIT Mechanisms}

Research has shown that EPIT induces Tregs. These cells are the centre of the immune regulatory effect and they inhibit Th2 cells. EPIT-induced Tregs also express a large repertoire of homing receptors suggesting that Tregs are able to migrate to various sites of allergen exposure (i.e., skin, lung and gut), suppress local immune responses to allergen stimulation, and potentially induce tolerance [24].

\section{IDIT Mechanisms}

According to intradermal grass pollen immunotherapy phase 2 trial in adults with moderate-tosevere allergic rhinitis, the results relevant with B cells, have shown an elevation in allergen-specific IgE levels and also observed on $P$ pratense-specific $\operatorname{IgG}$ and $\operatorname{IgE}$ titers to the main grass allergens even though there wasn't a difference on IgG4 responses [39]. Additionally, as for T cell responses, they observed higher expression of the Th2 marker CRTH2 and lower expression of Th1 related chemokine receptor CXCR3 on T cells which are cultured from skin punch biopsy explants in the IDIT group. This results suggests that $\mathrm{IgE}$ synthesis occurs via local priming of cutaneous Th2 responses [39] and that IDIT is not sufficient to activate an allergen-specific IgG response in the humoral arm of the immune system.

\section{LNIT Mechanisms}

Despite the lack of clinical trials and applications of LNIT, this route of immunotherapy has the potential to modulate immune responses systemically and in the local nasal airways. After LNIT with Peritaria allergen, inflammatory infiltration has decreased at local sites. In murine models, it was observed that although specific IgE reduced in the serum, the levels of specific and total IgA were increased in the saliva after LNIT [40]. Nonetheless, uncertain immunological mechanisms of LNIT are waiting to be enlightened. 


\section{Mast cells and Basophils}

The effect of mast cells and basophils on AIT mechanism can be classified as early desensitization and late responses in tissues. The early desensitization of mast cells and basophils are a result of AIT and displays lower responsiveness to allergens even if the allergen-specific IgE levels have increased at the beginning of immunotherapy [6]. Additionally, late effects of AIT on mast cells and basophils based on the attenuation in tissue infiltration and diminishment in releasing of their mediators [41] (Figure 2). In addition, the allergen binds to IgE, which has already bound to the surface receptor FceRI on mast cells and basophils, triggers crosslinking of the receptors and as a result activating these cells. It is thought that IgG antibodies also play a role in modulating mast cell responses through the stimulation of inhibitory networks, after binding to FcrRIIA and FcyRIIB receptors on mast cells [41]. Furthermore, different subclasses of $\mathrm{IgG}$, which are produced during the process of AIT also inhibit IgE-mediated basophil degranulation. Moreover, it was demonstrated that the most effective antibodies for suppressing FceRI on basophils were IgG3 and IgG2 [42]. In addition to early sensitization mechanism related to basophils, include rapid upregulation of histamine type 2 receptor (H2R) which has a suppressive effect on FceRI-mediated activation and degranulation of these cells. This mechanism of early allergen tolerance was determined in patients ongoing venom immunotherapy [41]. However, the mechanism remains to be elucidated.

\section{Allergen-specific, Regulatory $\mathbf{T}$ and Follicular Helper $\mathbf{T}$ cells}

Thymic or natural Tregs (nTregs), which are subsets of Tregs, are prone to perpetuate tolerance to self-antigens. Peripheral T cell tolerance is maintained with the generation of allergen-specific Tregs and reducing the Th2 cell numbers [43]. Immune response to allergens is a consequence of the balance between allergen-specific Tr1 cells and allergen-specific Th2 cells, which have a major role in the development of an allergy. It was shown that $\operatorname{Tr} 1$ cells apply their effect through cell-to-cell interactions by PD-1 and/or CTLA-4 also by means of cytokine products like IL-10 and TGF- $\beta$ [44]. Immunological studies with allergen-peptide-MHCII tetramers and deep sequencing of $\mathrm{T}$ cell receptor repertoires have demonstrated that allergen-specific Foxp3+ Tregs predominate over the response in healthy individuals. On the other hand, the coexistence of Tregs and memory/effector Th2 cells in allergic individuals is most likely due to the recognition of different antigenic epitopes in the same certain allergen by these cell subsets [31]. In a different study with MHC class II tetramers, which have used to sort allergenspecific CD4+ T cells, IL-4, IFN-g and IL-10 cytokine-secreting cells, has shown that HDM-specific subcutaneous immunotherapy results in a decline of allergic symptoms which correlates with Der $\mathrm{p}$ 1-specific Treg cell subsets as well as IL-22-secreting CD4+T-cell responses [45]. This data supports alterations in antigen-specific Tregs during the AIT. Besides, different study with Der 1 and Pam3CSK4, a synthetic TLR2 ligand, illustrated that Der $\mathrm{p} 1$ IT diminished CD8+CD25+CD137+ Treg frequency and decreased nNO (nasal nitric oxide) levels. On the other hand, Pam3CSK4 were able to modulate CD137 by cross-linking and retains FoxP3 expression of the CD8+CD25+ Tregs. These data propose that Pam3CSK4 participates in controlling allergic inflammatory diseases through CD8+ CD25+ Treg cells [46]. In addition, SLIT, OIT and EPIT induce the alteration in epigenetically, especially hypomethylation in the FoxP3 promoter region in Tregs. These changes are responsible for Tregs suppressive functions as well as prolonged production of Tregs $[47,48]$.

It has been taken for granted that allergen-specific Tregs, allergen-specific and non-specific effector $\mathrm{T}$ cells demonstrate phenotypic heterogeneity, which are not completely enlightening. In a study with patients who has peanut allergy has demonstrated that there have changes in genes of individual CD4+ T cells during OIT which have sorted with peanut-MHC dextramers. Furthermore, more data from the same study implied that OIT induces 
peanut-specific $\mathrm{T}$ cells in order to shift to anergic, memory T-cell phenotype (CD28lowKi67low) [49]. Based on the data from $\mathrm{T}$ cell receptor (TCR) analysis combined with single-cell RNA-seq demonstrates profiling $\mathrm{T}$ regulatory cell and conventional CD4+FoxP3- T cells [50]. The pathogenic subset of allergen-specific $\mathrm{T}$ cells, Th2A are characterized by a high expression of prostaglandin $\mathrm{D} 2$ receptor (CRTH2) and CD161 and CD49d and downregulation of $\mathrm{CD} 27, \mathrm{C}-\mathrm{C}$ chemokine receptor (CCR)7, CD7, and CD45RB [51]. These antigen-specific Th2 cells were found at the centre of the allergic process in atopic individuals and display various phenotypic and functional features distinctive from conventional Th2 cells and were preferentially absent during AIT [52]. Also, prolong SCIT and SLIT with grass-pollen were a clinical improvement during 2 years of treatment and were associated with reduced frequency of the allergen-specific CRTH2+ CCR4+CD27-CD4+Th2 cells [53]. Likewise, after 52 weeks of SLIT, HDM-reactive IL-5+ IL-13+ CD27- CD161+ CD4+ cells and ST2+ CD45RO+ CD4+ Th2 cells were decreased in HDM-allergic patients [54].

Understanding the alteration induced in $\mathrm{T}$ cells, which support successful immunotherapy remains unexplored. Data from another peanut IT study, indicates that in the period of IT, anergic memory and nonallergic antigen-specific CD4+ $\mathrm{T}$ cells remarkably induced in immune-tolerant individuals. Distinct phenotypic clusters of $\mathrm{CD} 4+\mathrm{T}$ cells were identified according to their markers. Th2 "allergic" as IL-4+/IL-13+, "nonallergic" as IFN- $\gamma+$, "regulatory" as FOXP3+/CD25+/IL-10+, and "anergic" type identified as CD28-/CD38-/IFN- $\gamma /$ IL-4-/IL-13-/IL-10in CD4+ T-cell subsets. Furthermore, data present antigen-specific CD4 $\mathrm{T}$ cells clonally expanded during OIT has shown the capability to transform into anergic and nonallergic phenotypes from an allergic and regulatory phenotypes [49].

In addition, another subtype of $\mathrm{T}$ cells, follicular helper T (Tfh) cells effect on SCIT has shown with reduced frequency of Tfh cells in AIT-treated patients. However, when it comes to the observation of immunologically related genes such as FOXP3, CCR8, LAG3, CD70, CCL5, LGALS3, ENC1 between CXCR5hi and CXCR5low subtypes of Tfh cells from the same donor, they were independent of AIT [55]. Among Tfh cells, Tfh2 subtype has unique with IL-4 secretion. It has been shown that after AIT with Der p 1, antigen-specific IL-4+ Tfh cell numbers decreased together with the remission of clinical symptoms from allergic rhinitis patients [56]. Nonetheless, the main mechanism of reduced frequency of Tfh cells in AIT remains unknown.

\section{Regulatory B cells}

Bregs are one of the main players of sustaining allergen tolerance, even if the mechanism of inducing tolerance is not fully understood. What is known, Bregs could support AIT through induction of Tregs, direct or indirect suppression of effector $\mathrm{T}$ cells by inhibiting dendritic cell (DC) [57]. Bregs are capable of inhibiting allergen-specific $\mathrm{T}$ cell proliferation, which is activated via the secretion of their marker cytokine, IL-10 [58]. Furthermore, it has been proven that early response to AIT requires IL-10 induction in B cells [59]. In a clinical study with grass-pollen allergic patients undergoing AIT, data demonstrates the success of long-term therapy. Moreover, PD-L1 expression was allergen-specifically up-regulated on circulating B cells was also indicated with local gene expression analysis. During this longterm therapy, it was demonstrated that in the nasal mucosa IL-10+ B cells were increased [58].

A human regulatory B cell subset which plays a role in tolerance to allergens was identified as CD73-CD25+CD71+ BR1 cells that produce IL-10 and IgG4-producing antibody-forming cells essentially develop from BR1 cells [36]. A recent study has shown that Breg cell subsets have gone to alteration between responder and non-responder patients during 2 years after HDM extract subcutaneous AIT. BR1 cells produces IL-1RA in addition to IL-10. Moreover, IL-10+IL1RA+Breg cells were expanded and the cell count was higher among the responders [37]. BR1 cells could suppress the proliferation of antigen-specific CD4+ T cells. On the other hand, 
IL-10 secreting B cells which are allergen-specific have demonstrated increased numbers, up to 5-fold, after venom immunotherapy (VIT) initialized. Also these IL-10+ Bregs can upregulate IgG4 secretion while suppressing Th cell proliferation [36]. Moreover, allergen-specific B cells have shown upregulation of CCR5 expression during VIT. However, the function and impact have not been revealed yet [60]. In another clinical trial with peanut OIT, increased levels of circulating allergen-specific B cells were also observed [61]. Current studies support remarkably B cell effect with AIT-driven responses.

\section{Innate lymphoid cells}

ILCs are transcriptionally and functionally similar to the T-cell and the subsets, yet the important difference is the lack of clonally distributed specific antigen receptors on their cell membrane [62]. ILCs can be divided into three subgroups based on their transcriptional factors and cytokine profiles. Group 1 ILCs (ILC1s) commonly require T-bet (transcriptional factor) for development and their main effector cytokine known as IFN- $\gamma$. Development of group 2 ILCs (ILC2s) controls by GATA-3 and express a cytokine profile similar to Th2 cells whereas group 3 ILCs (ILC3s) are contingent on retinoic acid-related orphan receptor gamma $\mathrm{t}$ (ROR $\gamma \mathrm{t})$ with the expression of IL-17 and IL-22 [63, 64]. As it seems, ILCs are highly plastic cells, which respond to stress signals through their cytokines, cell-surface receptors and lipid mediators induced by microbes and allergens [62]. ILC2s were observed as the dominant subtype of ILCs in the circulation of allergic patients with grass pollen allergy receiving AIT [65]. Another study was performed to assess the levels of ILC subsets in allergic rhinitis (AR) patients to house dust mite (HDM)-specific immunotherapy. AIT patients who have responded to AIT and healthy subjects demonstrated a similar reduction in circulating ILC2s. On the contrary, ILC1s frequency increased in both groups. As for ILC3 cells, natural cytotoxicity receptor (NCR)+ expression was lower in clinical responders com- pared to healthy control [66]. These results suggest AIT may shift from ILC2s to ILC1s and affects the frequency of ILC3s. However, more data must be provided to elucidate the mechanism of ILCs in AIT. A separate study showed similar results using a different allergen treatment by suppression of peripheral ILC2s during the pollen season in SCITtreated patients [67].

\section{Dendritic Cell Subsets}

In addition to basophils and mast cells, many other cell types can contribute to early immunotherapy responses. APCs can bind and internalize allergen-IgE immune complexes and therefore enhance allergen-specific $\mathrm{T}$ cell activation [68]. Recent studies described the main role of Tregs and classical/conventional dendritic cells (cDCs) related with oral tolerance, which requires the CCR7 dependent fundamental migration of cDCs from the lamina propria (LP) to draining mesenchymal lymph nodes (MesLNs) [69, 70]. It has been showed that SLIT induces Tregs in mice through oral cDCs with the CD103-CD11b+ phenotype exhibit retinoic acidproducing activity and changes naive $\mathrm{CD} 4+\mathrm{T}$ cells into Foxp $3+$ Tregs in vitro in a TGF- $\beta$ dependent and retinoic acid-dependent way. Oral CD103$\mathrm{CD} 11 \mathrm{~b}+\mathrm{cDCs}$ transport sublingual antigens to submandibular lymph nodes hereby induce antigen-specific Treg cells [69], as well as another type of dendritic cell, CD103+ cDCs, are capable of transport orally administered soluble antigens to the MesLNs of mice through CCR7-dependent mechanism [71]. CD103+DCs is also known as tolerogenic APCs and can lead to the differentiation of $T$ cells into Tregs [72], through their ability to express indoleamine 2,3-dioxygenase (IDO), an enzyme comprises tryptophan catabolism [73].

Recent studies suggest that DCs are the connecting bridge between innate and adaptive immune system via their tolerance induction abilities thereby may contribute to novel approaches of AIT routes. However, most of the new observations of DCs subsets in animal models must be also confirmed in humans. 


\section{Relationship among the responses of $\lg E$, IgG and $\lg A$}

Subcutaneous and sublingual treatment of AIT causes the early increase in allergen-specific IgE in serum but it is only temporary. Increased $\operatorname{IgE}$ concentrations can result in adverse effects and allergic symptoms. On the other hand, perpetuated immunotherapy paves the way for reducing the levels of allergen-specific IgE which may promote long-term clinical tolerance [53]. Additionally, allergen-specific IgE levels in serum are prone to decrease over time, regardless of regular and increasing doses of allergen exposure [74] (Figure 2).

According to literature reports, an essential mechanism of immune tolerance to allergens is likely to involve an induction of $\operatorname{IgG} 4$, which captures the allergen before it reaches IgE. When IgG4 crosslinks with FcyRIIb, which is located on the surface of mast cells or basophils, this engagement prevents the activation of these cells $[6,74,75]$. Evidence of an IgG-FcyRIIb link was demonstrated in foodallergic mice models [76]. Conclusion of IgG4 related reports suggests that AIT-induced allergen specific IgGs may block mast cell degranulation [68] and downregulate IL-4 secretion thus conducts Tregs and Th2 balance in allergic individuals [4] (Figure 2). Although there have been significant improvements in our current understanding on the mechanisms and basic contributions of humoral IgG, additional pathways need to be elucidated. The constricted perspective on allergen-specific IgG4 in AIT have omitted that other immunoglobulin subclasses in human allergic disease may contribute to the blocking and inhibitory response of IgG [74]. In vitro assays using IgG subclasses, other than IgG4, have shown the effector cell suppression via blocking IgE-allergen binding [75].

In spite of the fact that other subclasses of IgG induction during AIT are not fully understood, there is growing evidence of IgA relevant to tolerogenic potential. In an allergic mouse model, animals sensitized with egg white have given information about IgA in AIT. After 12 days of administration, allergen-specific IgA levels were higher in OIT mouse with short-term treatment [77]. A recent human OIT study has reported that during egg OIT, egg- and component-specific IgA, IgA1 and IgA2 levels in plasma also increased in patients who responded to therapy. Ratios of $\operatorname{IgG} 4$, IgA, and $\operatorname{IgA} 2$ to $\operatorname{IgE}$ may be useful to assess the benefit and clinical response to egg OIT. It has been suggested that IgG4 and IgA play a protective role after OIT was stopped [78]. Furthermore, salivary allergen-specific IgA was established as an effective biomarker in peanut sublingual AIT in humans, which is also correlated with the rating of tolerance posterior to AIT [74]. A recent study demonstrated that after 2 years of SCIT with HDM, Der p1-specific IgA increased in plasma relative to baseline levels. Der p 1-specific IgG4 levels increased in responders within 2 years of AIT [37]. Whole mechanisms underlay the allergen-specific IgA responses in AIT is required for the development of therapeutic strategies.

\section{Promising Biomarkers for Diagnosis, Evaluating the Effectiveness of AIT and Inducing Immune Tolerance}

AIT research using a combination of biological agents has become more frequent in recent years. In spite of the efficacy of AIT is adequate, not all patients respond to AIT and benefit from the treatment. Numerous studies assist to disclose the mechanism of AIT, though the recent knowledge is inadequate to predict the clinical response to the treatment owing to deprivation of surrogate biomarkers. Nevertheless, several biomarkers are candidates to predict positive clinical outcomes and evaluate AIT efficacy and acquire tolerance [79]. We will discuss this in subtopics.

\section{Basophil Response}

Basophil responsiveness has been considered as a potential biomarker for the assessment of immunotherapy outcome. In a recent study, the allergen threshold sensitivity (CD-Sens) was used through the basophil activation test in order to predict clinical efficacy and keep track of immune responses to AIT. The study was performed with allergic rhinitis patients who received SLIT and have an allergy to a kind of pollen allergen, Parietaria. After 12 months 
of SLIT, the patients showed reduced severity of allergic symptoms and increased tolerability of basophils to the Parietaria with the guidance of CD-Sens through both CD63 and CD203c. Nonetheless, corresponding with clinical symptoms, only CD203c showed a correlation in patients [80].

It is known that immunotherapy inhibits histamine release from basophils, yet the assay is impractical and there is inadequate data in IT withdrawal symptoms. In order to provide these requirements, fluorochrome-labelled diamine oxidase (DAO) which has the potential to quantify the intracellular histamine was tested as a surrogate marker for detecting histamine release in allergic rhinitis patients undergoing SCIT and SLIT. As a result, intracellularly labelled DAO+ and surface expression of CD63, CD203c, and CD107a levels in whole-blood basophils indicated diminished basophil responsiveness and histamine release after SCIT and SLIT. In addition, this reduction was accompanied by a correlation with reduced allergic rhinitis symptoms [81]. Thus, these novel biomarkers related to basophil activation could be used to predict the outcome of AIT responsiveness and could be used to monitor the clinical outcomes and positive response to immunotherapy.

\section{Observing Total IgE, Allergen-specific IgE and IgG4}

In addition to clinical symptoms, inclusion criteria for initiating AIT includes elevated serum-specific IgE (sIgE) levels upon allergen exposure [82]. Different studies have indicated that during the first few months of AIT, there was no clinical change of allergen-specific IgE serum levels in patients, but after 6 to 12 months, a progressive decrease was observed in the sIgEs in long-term AIT studies [83]. Moreover, allergen-specific IgE levels decreased gradually after the initial increase during immunotherapy in food allergy studies without consistent clinical improvement [83, 84]. Similar to sIgE, a transient primary increase was followed by a decreased observed of total $\operatorname{IgE}(\operatorname{tg} E)$. However, there is a wide discrepancy between different studies [33]. Using the $\operatorname{sgE} / \operatorname{tg}$ E ratio resulted in inconsistent data when used as a predictive marker of clinical response to AIT. Additionally, the sIgE/tIgE ratio might have played a role in predicting responsiveness to AIT with pollen-allergic patients. However, a successive randomized, controlled, open-labelled study could not replicate the results [85]. This data was supported by another study with mono-sensitized patients to house dust might during AIT which demonstrated a significant correlation between the ratio of $\operatorname{sg} \mathrm{E} /$ tIgE and alterations on visual analogue and rhinitis symptom scores [86]. Nevertheless, additional research and clarification is essential for the use of $\mathrm{SIgE} / \mathrm{tgE}$ ratio and maybe promising potential marker for response to AIT, especially for food allergies.

Another antibody isotype, which has shown elevated levels within the first months of AIT is allergen-specific IgG4 (sIgG4) [81, 87]. Functional activities of $\operatorname{IgG}$ can assess with IgE-facilitated allergen binding to $\mathrm{B}$ cells (IgE-FAB) which measures the serum inhibitory capacity. In addition to this flow cytometry-based assay, it can be measured with a fluorescent immunoassay which is called Immunosolid-phase allergen chip (ISAC) [88, 89]. This method contains immobilization of allergens on a microarray chip which allows simultaneous measurement of specific IgE antibodies to allergen sources, and allergen-specific IgG and $\mathrm{IgG}_{4}$ measurements. However, it is a semiquantitative measurement and the composition of the allergen extracts are not standardized [89]. A different study with cat allergic patients has reported the therapeutic value of IgG as part of AIT. Results indicate the durability of high-affinity antibodies also powerful in the context of neutralizing which has shown effective protection at low serum concentrations in the clinic. The de novo IgG4 response, which was induced during AIT, decreased after discontinuation of treatment [90], while the persistence of blocking antibodies was associated with clinical tolerance [74]. In brief, there is a need for further research to improve the efficacy of antibodies and potential roles as biomarkers.

\section{T Regulatory Cells and IL-10+ Subset}

There is a plethora of research on the role of allergen-specific Tregs in the initiation and perpetuation of healthy immune responses to allergens [33, 91]. 
After immune tolerance induced via SLIT, it led to an expansion in Treg cell count and an increased allergen-specific IgG4 levels in most of the patients due to suppression of $\mathrm{Th} 2$ responses by the second year of AIT. Furthermore, the induced cell population was identified as CD4+CD127-CD45RA-CD25high cell subset (similar to activated memory Treg), which was accompanied by IL-10 production [92], even though the suppressive capacity of these specific Treg subsets requires further studies. In addition to these findings, a 3 year follow-up study with patients undergoing subcutaneous house dust mite (HDM)-specific immunotherapy has shown that the alteration in allergen-specific Treg cells, $75 \%$ of patients has demonstrated an elevation in IL-10 T regulatory (Tr) 1 cell numbers during AIT [45]. Furthermore, 30 weeks later from the start of therapy, Der $\mathrm{p}$ 1-specific IL-10 and IL-22 secretion were higher than baseline levels. However, after 3 years of AIT, the only remaining Tregs with high frequency were IL-10+ Der p 1-specific ones which were also associated with improved allergic symptoms [45]. These findings support the idea of monitoring peripheral allergy tolerance and clinical response of HDM-specific SCIT by using Der p 1-MHC class II tetramer. When SLIT combined with systemic administration of intraperitoneal injection of the low doses of IL-2 monoclonal antibody in mice, this combined therapy leads to enhancement in the frequency of IL-10-secreting CD4+CD25+Foxp3+ Tregs in lymph nodes and lamina propria, which is a promising novel approach for humans in AIT [93].

\section{The Potential of Dendritic Cells}

Depending on their maturation, location and cytokine exposure, DCs can establish and sustain an allergic inflammation as proallergic DC2s or support the condition of immune tolerance as tolerogenic regulatory dendritic cells (DCregs) [91, 94]. A recent study focused on the possible correlation between adjustments of molecular signatures related to peripheral blood DCs and the clinical enhancement in individual patients. After 4 months of grass-pollen immunotherapy, it was demonstrated that C1QA,
Fc $\gamma$ RIIIA, FTL and SLCO2B1, which are associated markers with DCreg cells were triggered. The induction of FcyRIIIA correlated with clinical efficacy, which occurred only after 2 months of AIT [95]. Congruently, down-regulated levels of DC2s markers CD141, GATA3, OX40L, and receptor-interacting serine/threonine-protein kinase 4 (RIPK4) were determined with the clinical improvement after 4 months of AIT. However, those markers cannot be excluded from other cells to discriminate from DCs, which may also contribute to alterations in molecular signatures observed in the blood after AIT. Nevertheless, they inferred that these alterations reflect the efficacy of AIT on innate immune mechanisms which contains monocyte-derived dendritic cells (MoDCs) and probably myeloid and plasmacytoid DCs [95]. In another study related to allergen-specific tolerance demonstrated that the polarization from MoDCs was in the direction of DCreg cell profile [96]. These findings verify that there is a link between the clinical efficacy of AIT and blood DCs. Furthermore, molecular signatures of DCs were connected to the clinically efficient AIT at the beginning of treatment [95]. However, candidate markers for determining the efficacy of AIT need to be confirmed with larger follow-up studies with many patients who undergo different routes of AIT.

\section{Conclusions}

The natural form of allergen or raw allergen extracts used in AIT might vary depending on the source $[97,98]$. Although it is an advantage that recombinant allergens are standardized, the clinical response to the whole allergen source may not be entirely regulated by single antigens [99]. Due to the risk of stimulating IgE production through recombinant allergens, there is a limited use of manufactured allergens.

The result from SCIT and SLIT studies have shown a reduction in allergen-specific CD4 T-cell numbers with the presence of clinical improvement. Nevertheless, two years after treatment completion, it was observed that participants allergic parameters returned to the baseline [100]. The study supports 
the inefficiency of AIT at sustaining an immunological effect. The aim of AIT must be to preserve the benefits of therapy and stabilize this state. In addition, there is a shortage of reliable molecular and cellular biomarkers to monitor the therapeutic effect of vaccine therapies to indicate the clinical stage of tolerance to allergens [58].

\section{Competing Interests}

LC and MA declare they have no competing interests.

\section{Acknowledgments}

The authors' laboratories are supported by Swiss National Science Foundation Grant No. 310030-179428, Sean Parker Asthma and Allergy Center, Stanford University USA.

\section{References}

[1] W. van de Veen, and M. Akdis, "The use of biologics for immune modulation in allergic disease", Journal of Clinical Investigation, vol. 129, no. 4, pp. 1452-1462, 2019.

[2] O. Cromwell, D. Häfner, and A. Nandy, "Recombinant allergens for specific immunotherapy", Journal of Allergy and Clinical Immunology, vol. 127, no. 4, pp. 865-872, 2011.

[3] Z.-J. Xie, K. Guan, and J. Yin, "Advances in the clinical and mechanism research of pollen induced seasonal allergic asthma", American journal of clinical and experimental immunology, vol. 8, no. 1, pp. 1-8, 2019.

[4] O. Palomares, M. Akdis, M. Martín-Fontecha, and C.A. Akdis, "Mechanisms of immune regulation in allergic diseases: the role of regulatory $\mathrm{T}$ and B cells", Immunological Reviews, vol. 278, no. 1, pp. 219-236, 2017.

[5] R.S. Mueller et al., "Allergen immunotherapy in people, dogs, cats and horses - differences, similarities and research needs", Allergy: European Journal of Allergy and Clinical Immunology, vol. 73, no. 10, pp. 1989-1999, 2018.

[6] A. Głobińska et al., "Mechanisms of allergen-specific immunotherapy: Diverse mechanisms of immune tolerance to allergens", Annals of Allergy, Asthma and Immunology, vol. 121, no. 3. American College of Allergy, Asthma and Immunology, pp. 306-312, 01-Sep-2018.

[7] D.E.S. Larenas-Linnemann et al., "National clinical practice guidelines for allergen immunotherapy: An international assessment applying AGREE-II", Allergy: European Journal of Allergy and Clinical Immunology. 2018. Vol. 73. No. 3. P. $664-672$.

[8] M.A. Tosca, A. Licari, R. Olcese, G. Marseglia, O. Sacco, and G. Ciprandi, "Immunotherapy and asthma in children", Frontiers in Pediatrics, vol. 6, 2018.

[9] H. Hoover, B. Leatherman, M. Ryan, K. McMains, and M. Veling, "Evidence-based dosing of maintenance subcutaneous immunotherapy: a contemporary review of state- of-the-art practice", International Forum of Allergy and Rhinology, vol. 8, no. 7, pp. 806-816, Jul. 2018.

[10] A. Muraro et al., "EAACI guidelines on allergen immunotherapy: Executive statement", Allergy: European Journal of Allergy and Clinical Immunology, vol. 73, no. 4, pp. 739-743, 2018.

[11] M. Jutel et al., "International consensus on allergy immunotherapy", Journal of Allergy and Clinical Immunology, vol. 136, no. 3, pp. 556-568, 2015.

[12] O. Pfaar, H. Lou, Y. Zhang, L. Klimek, and L. Zhang, "Recent developments and highlights in allergen immunotherapy", Allergy: European Journal of Allergy and Clinical Immunology, vol. 73, no. 12, pp. 2274-2289, 2018.

[13] F. Porcaro, G. Corsello, and G.B. Pajno, "SLIT's Prevention of the Allergic March", Current Allergy and Asthma Reports, vol. 18, no. 5, 2018.

[14] H. Nolte and J. Maloney, "The global development and clinical efficacy of sublingual tablet immunotherapy for allergic diseases", Allergology International, vol. 67, no. 3, pp. 301-308, 2018.

[15] C. Blanco, R. Bazire, L. Argiz, and J. Hernández-Peña, "Sublingual allergen immunotherapy for respiratory allergy: A systematic review", Drugs in Context, vol. 7, 2018.

[16] K. Lund, H. Kito, M.B. Skydtsgaard, H. Nakazawa, K. Ohashi-Doi, and S. Lawton, "The Importance of Tablet Formulation on Allergen Release Kinetics and Efficiency: Comparison of Freeze-dried and Compressed Grass Pollen Sublingual Allergy Immunotherapy Tablet Formulations", Clinical Therapeutics, vol. 41, no. 4, pp. 742-753, 2019.

[17] R.L. Wasserman et al., "Reaching for best practices in food oral immunotherapy: Report on the second annual Food Allergy Support Team meeting", Annals of Allergy, Asthma and Immunology, vol. 123, no. 2, pp. 129-130.e2, 2019.

[18] K. ichi Nagakura et al., "Low-dose oral immunotherapy for children with anaphylactic peanut allergy in Japan", Pediatric Allergy and Immunology, vol. 29, no. 5, pp. 512-518, 2018.

[19] J. Mäntylä et al., "The effect of oral immunotherapy treatment in severe IgE mediated milk, peanut, and egg allergy in adults", Immunity Inflammation and Disease, vol. 6, no. 2, pp. 307-311, Jun. 2018.

[20] D.K. Chu et al., "Oral immunotherapy for peanut allergy (PACE): a systematic review and meta-analysis of efficacy and safety", The Lancet, vol. 393, no. 10187, pp. 2222-2232, 2019.

[21] U. Nurmatov et al., "Allergen immunotherapy for IgEmediated food allergy: a systematic review and metaanalysis", Allergy: European Journal of Allergy and Clinical Immunology, vol. 72, no. 8, pp. 1133-1147, 2017.

[22] G. Senti et al., "Intralymphatic Immunotherapy: Update and Unmet Needs", International Archives of Allergy and Immunology, vol. 178, no. 2, pp. 141-149, 2019. 
[23] S. Esposito et al., "Epicutaneous immunotherapy in rhinoconjunctivitis and food allergies: A review of the literature", Journal of Translational Medicine, vol. 16, no. 1, 2018.

[24] J.A. Bird, M. Sánchez-Borges, I.J. Ansotegui, M. Ebisawa, and J.A.O. Martell, "Skin as an immune organ and clinical applications of skin-based immunotherapy", World Allergy Organization Journal, vol. 11, no. 1, 2018.

[25] G. Senti et al., "Epicutaneous allergen administration as a novel method of allergen-specific immunotherapy", Journal of Allergy and Clinical Immunology, vol. 124, no. 5, pp. 997-1002, 2009.

[26] L. Mondoulet, V. Dioszeghy, M. Ligouis, V. Dhelft, C. Dupont, and P.H. Benhamou, "Epicutaneous immunotherapy on intact skin using a new delivery system in a murine model of allergy", Clinical and Experimental Allergy, vol. 40, no. 4, pp. 659-667, 2010.

[27] A.W. Burks, H.A. Sampson, M. Plaut, G. Lack, and C.A. Akdis, "Treatment for food allergy", Journal of Allergy and Clinical Immunology, vol. 141, no. 1. pp. 19, 2018.

[28] G. Du et al., "Intradermal vaccination with hollow microneedles: A comparative study of various protein antigen and adjuvant encapsulated nanoparticles", Journal of Controlled Release, vol. 266, pp. 109-118, 2017.

[29] J.J. Tsai, E.C. Liao, F.H. Tsai, C.C. Hsieh, and M.F. Lee, "The effect of local nasal immunotherapy in allergic rhinitis: Using strips of the allergen dermatophagoides pteronyssinus", Journal of Asthma, vol. 46, no. 2, pp. 165-170, 2009.

[30] G.B. Pajno et al., "Children's compliance with allergen immunotherapy according to administration routes [1]", Journal of Allergy and Clinical Immunology, vol. 116, no. 6, pp. 1380-1381, 2005.

[31] B.N. Lambrecht and H. Hammad, "The immunology of the allergy epidemic and the hygiene hypothesis", Nature Immunology, vol. 18, no. 10. pp. 1076-1083, 2017.

[32] H.A. Sampson, L. O'Mahony, A.W. Burks, M. Plaut, G. Lack, and C.A. Akdis, "Mechanisms of food allergy", Journal of Allergy and Clinical Immunology, vol. 141, no. 1, pp. 11-19, Jan. 2018.

[33] C.A. Akdis and M. Akdis, "Mechanisms of allergen-specific immunotherapy and immune tolerance to allergens", World Allergy Organization Journal, vol. 8, no. 1, 2015.

[34] C. Möbs, C. Slotosch, H. Löffler, T. Jakob, M. Hertl, and W. Pfützner, "Birch Pollen Immunotherapy Leads to Differential Induction of Regulatory $\mathrm{T}$ Cells and Delayed Helper T Cell Immune Deviation", The Journal of Immunology, vol. 184, no. 4, pp. 2194-2203, 2010.

[35] S. Radulovic, M.R. Jacobson, S.R. Durham, and K.T. Nouri-Aria, "Grass pollen immunotherapy induces Foxp3expressing CD4+CD25+ cells in the nasal mucosa", Journal of Allergy and Clinical Immunology, vol. 121, no. 6, pp. 1467-1472, 2008.
[36] W. Van De Veen et al., "IgG4 production is confined to human IL-10-producing regulatory B cells that suppress antigen-specific immune responses", Journal of Allergy and Clinical Immunology, vol. 131, no. 4, pp. 12041212, 2013.

[37] T. Boonpiyathad et al., "Role of Der p 1-specific B cells in immune tolerance during 2 years of house dust mitespecific immunotherapy", Journal of Allergy and Clinical Immunology, vol. 143, no. 3, pp. 1077-1086.e10, 2019.

[38] S.N. Freiberger, M. Zehnder, G. Gafvelin, H. Grönlund, T.M. Kündig, and P. Johansen, "IgG4 but no IgG1 antibody production after intralymphatic immunotherapy with recombinant MAT-Feld1 in human", Allergy: European Journal of Allergy and Clinical Immunology, vol. 71, no. 9, pp. 1366-1370, 2016.

[39] A. Slovick et al., "A randomised placebo-controlled trial investigating efficacy and mechanisms of low-dose intradermal allergen immunotherapy in treatment of seasonal allergic rhinitis", Efficacy and Mechanism Evaluation, vol. 3, no. 10, pp. $1-80$, Dec. 2016.

[40] Y. Liu and J.-J. Tsai, "Production of Salivary Immunoglobulin A and Suppression of Dermatophagoides pteronyssinus-Induced Airway Inflammation by Local Nasal Immunotherapy", Int Arch Allergy Immunol, vol. 138, no. 2, 2005.

[41] C.T. Cady et al., "IgG antibodies produced during subcutaneous allergen immunotherapy mediate inhibition of basophil activation via a mechanism involving both Fc $\gamma$ RIIA and Fc $\gamma$ RIIB", Immunology Letters, vol. 130, no. $1-2$, pp. $57-65,2010$.

[42] D. MacGlashan and R.G. Hamilton, "Parameters determining the efficacy of CD32 to inhibit activation of Fc $\in$ RI in human basophils", Journal of Allergy and Clinical Immunology, vol. 137, no. 4, pp. 1256-1258.e11, 2016.

[43] C.A. Akdis and M. Akdis, "Mechanisms of immune tolerance to allergens: Role of IL-10 and Tregs", Journal of Clinical Investigation, vol. 124, no. 11, pp. 46784680, Nov. 2014.

[44] M. Akdis et al., "Immune responses in healthy and allergic individuals are characterized by a fine balance between allergen-specific $\mathrm{T}$ regulatory 1 and $\mathrm{T}$ helper 2 cells", Journal of Experimental Medicine, vol. 199, no. 11 , pp. 1567-1575, 2004.

[45] T. Boonpiyathad et al., "Der p 1-specific regulatory T-cell response during house dust mite allergen immunotherapy", Allergy: European Journal of Allergy and Clinical Immunology, vol. 74, no. 5, pp. 976-985, 2019.

[46] Y.G. Tsai, K.D. Yang, Y.S. Wen, C.H. Hung, J.W. Chien, and C.Y. Lin, "Allergen-specific immunotherapy enhances $\mathrm{CD} 8+\mathrm{CD} 25+\mathrm{CD} 137+$ regulatory $\mathrm{T}$ cells and decreases nasal nitric oxide", Pediatric Allergy and Immunology, 2019.

[47] A. Syed et al., "Peanut oral immunotherapy results in increased antigen-induced regulatory $\mathrm{T}$-cell function 
and hypomethylation of forkhead box protein 3 (FOXP3)", Journal of Allergy and Clinical Immunology, vol. 133, no. 2, pp. 500-510, 2014.

[48] L. Mondoulet et al., "Gata3 hypermethylation and Foxp3 hypomethylation are associated with sustained protection and bystander effect following epicutaneous immunotherapy in peanut-sensitized mice", Allergy: European Journal of Allergy and Clinical Immunology, vol. 74, no. 1, pp. 152-164, 2019.

[49] J.F. Ryan et al., "Successful immunotherapy induces previously unidentified allergen-specific CD4+ T-cell subsets", Proceedings of the National Academy of Sciences of the United States of America, vol. 113, no. 9, pp. E1286-E1295, 2016.

[50] D. Zemmour, R. Zilionis, E. Kiner, A.M. Klein, D. Mathis, and C. Benoist, "Single-cell gene expression reveals a landscape of regulatory $\mathrm{T}$ cell phenotypes shaped by the TCR article", Nature Immunology, vol. 19, no. 3, pp. 291-301, 2018.

[51] E. Wambre et al., "A phenotypically and functionally distinct human TH2 cell subpopulation is associated with allergic disorders", Science Translational Medicine, vol. 9, no. 401, 2017.

[52] E. Wambre, "Effect of allergen-specific immunotherapy on CD4+ T cells", Current Opinion in Allergy and Clinical Immunology, vol. 15, no. 6, pp. 581—587, 2015.

[53] G.W. Scadding et al., "Effect of 2 years of treatment with sublingual grass pollen immunotherapy on nasal response to allergen challenge at 3 years among patients with moderate to severe seasonal allergic rhinitis: The GRASS randomized clinical trial", JAMA - Journal of the American Medical Association, vol. 317, no. 6, pp. 615-625, 2017.

[54] F. Ihara et al., "Identification of specifically reduced Th2 cell subsets in allergic rhinitis patients after sublingual immunotherapy", Allergy: European Journal of Allergy and Clinical Immunology, vol. 73, no. 9, pp. 1823-1832, 2018.

[55] V. Schulten et al., "Allergen-specific immunotherapy modulates the balance of circulating Tfh and Tfr cells", Journal of Allergy and Clinical Immunology, vol. 141, no. 2, pp. 775-777.e6, 2018.

[56] Y. Yao, Z.C. Wang, D. Yu, and Z. Liu, "Role of allergenspecific T-follicular helper cells in immunotherapy", Current Opinion in Allergy and Clinical Immunology, vol. 18, no. 6, pp. 495-501, 2018.

[57] W. Van De Veen, "The role of regulatory B cells in allergen immunotherapy", Current Opinion in Allergy and Clinical Immunology, vol. 17, no. 6, pp. 447-452, 2017.

[58] U.M. Zissler et al., "Early IL-10 producing B-cells and coinciding $\mathrm{Th} / \mathrm{Tr} 17$ shifts during three year grasspollen AIT", EBioMedicine, vol. 36, pp. 475-488, Oct. 2018.

[59] B. Stanic et al., "IL-10-overexpressing B cells regulate innate and adaptive immune responses", Journal of Aller- gy and Clinical Immunology, vol. 135, no. 3, pp. 771780.e8, 2015.

[60] T. Boonpiyathad et al., "High-dose bee venom exposure induces similar tolerogenic B-cell responses in allergic patients and healthy beekeepers", Allergy: European Journal of Allergy and Clinical Immunology, vol. 72, no. 3, pp. 407-415, 2017.

[61] S.U. Patil et al., "Peanut oral immunotherapy transiently expands circulating Ara h 2-specific B cells with a homologous repertoire in unrelated subjects", Journal of Allergy and Clinical Immunology, vol. 136, no. 1, pp. 125134.e12, 2015.

[62] J. Mjösberg and H. Spits, "Human innate lymphoid cells", Journal of Allergy and Clinical Immunology, vol. 138, no. 5, pp. 1265-1276, Nov. 2016.

[63] T. Hoyler et al., "The Transcription Factor GATA-3 Controls Cell Fate and Maintenance of Type 2 Innate Lymphoid Cells", Immunity, vol. 37, no. 4, pp. 634-648, 2012.

[64] T.Y.F. Halim, A. MacLaren, M.T. Romanish, M.J. Gold, K.M. McNagny, and F. Takei, "Retinoic-Acid-ReceptorRelated Orphan Nuclear Receptor Alpha Is Required for Natural Helper Cell Development and Allergic Inflammation”, Immunity, vol. 37, no. 3, pp. 463-474, 2012.

[65] V. Lombardi et al., "Circulating innate lymphoid cells are differentially regulated in allergic and nonallergic subjects", Journal of Allergy and Clinical Immunology, vol. 138, no. 1, pp. 305-308, 2016.

[66] W. Mitthamsiri, P. Pradubpongsa, A. Sangasapaviliya, and T. Boonpiyathad, "Decreased CRTH2 expression and response to allergen re-stimulation on innate lymphoid cells in patients with allergen-specific immunotherapy", Allergy, Asthma and Immunology Research, vol. 10, no. 6, pp. 662-674, 2018.

[67] M. Lao-Araya, E. Steveling, G.W. Scadding, S.R. Durham, and M.H. Shamji, "Seasonal increases in peripheral innate lymphoid type 2 cells are inhibited by subcutaneous grass pollen immunotherapy", Journal of Allergy and Clinical Immunology, vol. 134, no. 5, pp. 1193-1195.e4, 2014.

[68] J. Eckl-Dorna et al., "Allergen-specific antibodies regulate secondary allergen-specific immune responses", Frontiers in Immunology, vol. 10, no. JAN, p. 3131, Jan. 2019.

[69] Y. Tanaka, S. Fukumoto, and S. Sugawara, "Mechanisms underlying the induction of regulatory $\mathrm{T}$ cells by sublingual immunotherapy", Journal of Oral Biosciences, vol. 61 , no. 2 , pp. $73-77,2019$.

[70] T. Worbs et al., "Oral tolerance originates in the intestinal immune system and relies on antigen carriage by dendritic cells", Journal of Experimental Medicine, vol. 203, no. 3, pp. 519-527, Mar. 2006.

[71] B. Johansson-Lindbom et al., "Functional specialization of gut CD103+ dendritic cells in the regulation of tissueselective T cell homing", Journal of Experimental Medicine, vol. 202, no. 8, pp. 1063-1073, Oct. 2005. 
[72] C. Bussmann, J. Xia, J.P. Allam, L. Maintz, T. Bieber, and N. Novak, "Early markers for protective mechanisms during rush venom immunotherapy", Allergy: European Journal of Allergy and Clinical Immunology, vol. 65, no. 12, pp. 1558-1565, 2010.

[73] G. Matteoli et al., "Gut CD103+ dendritic cells express indoleamine 2,3-dioxygenase which influences $\mathrm{T}$ regulatory/T effector cell balance and oral tolerance induction”, Gut, vol. 59, no. 5, pp. 595-604, 2010.

[74] R. Jiménez-Saiz and S.U. Patil, "The Multifaceted B Cell Response in Allergen Immunotherapy", Current Allergy and Asthma Reports, vol. 18, no. 12, 2018.

[75] T.S. Dodev et al., "Inhibition of allergen-dependent IgE activity by antibodies of the same specificity but different class", Allergy: European Journal of Allergy and Clinical Immunology, vol. 70, no. 6, pp. 720-724, 2015.

[76] O.T. Burton et al., "Oral immunotherapy induces $\operatorname{IgG}$ antibodies that act through Fc $\gamma$ RIIb to suppress IgE-mediated hypersensitivity", Journal of Allergy and Clinical Immunology, vol. 134, no. 6, pp. 1310-1317.e6, 2014.

[77] A. Maeta, R. Katahira, M. Matsushima, H. Onishi, Y. Nakamura, and K. Takahashi, "Stepwise oral immunotherapy for 10 days in an egg-white allergy mouse model did not ameliorate the severity of allergy but induced the production of allergen-specific IgA", Bioscience, Biotechnology and Biochemistry, vol. 82, no. 12, pp. 2176-2179, 2018.

[78] B.L. Wright et al., "Component-resolved analysis of IgA, $\mathrm{IgE}$, and IgG4 during egg OIT identifies markers associated with sustained unresponsiveness", Allergy: European Journal of Allergy and Clinical Immunology, vol. 71, no. 11, pp. 1552-1560, 2016.

[79] C.A. Jakwerth et al., "Biomarkers for monitoring clinical efficacy of allergen immunotherapy for allergic rhinoconjunctivitis and allergic asthma: An EAACI position paper", Allergologie, vol. 41, no. 9, pp. 376-385, 2018.

[80] M. Caruso et al., "Basophil biomarkers as useful predictors for sublingual immunotherapy in allergic rhinitis", International Immunopharmacology, vol. 60, pp. 50-58, 2018.

[81] M.H. Shamji et al., "Basophil expression of diamine oxidase: A novel biomarker of allergen immunotherapy response", Journal of Allergy and Clinical Immunology, vol. 135, no. 4, pp. 913-921.e9, 2015.

[82] M.A. Calderõn et al., "Allergen immunotherapy: A new semantic framework from the European Academy of Allergy and Clinical Immunology/American Academy of Allergy, Asthma and Immunology/PRACTALL Consensus Report", Allergy: European Journal of Allergy and Clinical Immunology, vol. 68, no. 7. pp. 825-828, 2013.

[83] S.B. Sindher, A. Long, S. Acharya, V. Sampath, and K.C. Nadeau, "The Use of Biomarkers to Predict AeroAllergen and Food Immunotherapy Responses", Clinical
Reviews in Allergy and Immunology, vol. 55, no. 2. pp. 190-204, 2018.

[84] S.D. Narisety et al., "A randomized, double-blind, placebo-controlled pilot study of sublingual versus oral immunotherapy for the treatment of peanut allergy", Journal of Allergy and Clinical Immunology, vol. 135, no. 5, pp. 1275-1282.e6, 2015.

[85] G. Di Lorenzo et al., "Evaluation of serum s-IgE/total IgE ratio in predicting clinical response to allergen-specific immunotherapy", Journal of Allergy and Clinical Immunology, vol. 123, no. 5, pp. 1103-1110, 2009.

[86] G.B. Karakoc, M. Yilmaz, D.U. Altıntaş, and S.G. Kendirli, "Can Serum-Specific IgE/Total IgE Ratio Predict Clinical Response to Allergen-Specific Immunotherapy in Children Monosensitized to House Dust Mite?", Journal of Allergy, vol. 2012, pp. 1-5, 2012.

[87] J. Chen et al., "Specific immunoglobulin e and immunoglobulin G4 toward major allergens of house-dust mite during allergen-specific immunotherapy", American Journal of Rhinology and Allergy, vol. 31, no. 3, pp. 156160, 2017.

[88] M. Feng et al., "Functional and Immunoreactive Levels of IgG4 Correlate with Clinical Responses during the Maintenance Phase of House Dust Mite Immunotherapy", The Journal of Immunology, vol. 200, no. 12, pp. 38973904, Jun. 2018.

[89] A. Santosa et al., "Evaluation of the applicability of the Immuno-solidphase allergen chip (ISAC) assay in atopic patients in Singapore", Clinical and Translational Allergy, vol. 5, no. 1, 2015.

[90] J.M. Orengo et al., "Treating cat allergy with monoclonal IgG antibodies that bind allergen and prevent IgE engagement", Nature Communications, vol. 9, no. 1, 2018.

[91] O. Palomares, L. O'Mahony, and C.A. Akdis, "The many routes of dendritic cells to ensure immune regulation", Journal of Allergy and Clinical Immunology, vol. 127, no. 6, pp. $1541-1542,2011$.

[92] A. Suárez-Fueyo et al., "Grass tablet sublingual immunotherapy downregulates the $\mathrm{TH} 2$ cytokine response followed by regulatory T-cell generation", Journal of Allergy and Clinical Immunology, vol. 133, no. 1, 2014.

[93] P.L. Smaldini, F. Trejo, J.L. Cohen, E. Piaggio, and G.H. Docena, "Systemic IL-2/anti-IL-2Ab complex combined with sublingual immunotherapy suppresses experimental food allergy in mice through induction of mucosal regulatory T cells", Allergy: European Journal of Allergy and Clinical Immunology, vol. 73, no. 4, pp. 885-895, 2018.

[94] M.H. Shamji and S.R. Durham, "Mechanisms of allergen immunotherapy for inhaled allergens and predictive biomarkers", Journal of Allergy and Clinical Immunology, vol. 140, no. 6, pp. 1485-1498, Dec. 2017.

[95] C. Gueguen et al., "Changes in markers associated with dendritic cells driving the differentiation of either T H 2 
cells or regulatory $\mathrm{T}$ cells correlate with clinical benefit during allergen immunotherapy", Journal of Allergy and Clinical Immunology, vol. 137, no. 2, pp. 545-558, 2016.

[96] A. Zimmer et al., "A regulatory dendritic cell signature correlates with the clinical efficacy of allergen-specific sublingual immunotherapy", Journal of Allergy and Clinical Immunology, vol. 129, no. 4, pp. 1020-1030, 2012.

[97] S.R. Durham et al., "SQ-standardized sublingual grass immunotherapy: Confirmation of disease modification 2 years after 3 years of treatment in a randomized trial", Journal of Allergy and Clinical Immunology, vol. 129, no. 3, 2012.
[98] G. Du Toit et al., "Randomized trial of peanut consumption in infants at risk for peanut allergy", New England Journal of Medicine, vol. 372, no. 9, pp. 803 -813, 2015.

[99] R. Valenta, R. Campana, M. Focke-Tejkl, and V. Niederberger, "Vaccine development for allergen-specific immunotherapy based on recombinant allergens and synthetic allergen peptides: Lessons from the past and novel mechanisms of action for the future", Journal of Allergy and Clinical Immunology, vol. 137, no. 2, pp. 351-357, 2016.

[100] A. Renand et al., "Synchronous immune alterations mirror clinical response during allergen immunotherapy", Journal of Allergy and Clinical Immunology, vol. 141, no. 5, pp. 1750-1760.e1, May 2018.

(C) Lacin Cevhertas, Mübeccel Akdis, 2019 This work is licensed under a Creative Commons Attribution 4.0 International License

Received 05.09.2019 Accepted 15.09.2019

\title{
Разнообразие механизмов аллерген-специфической иммунотерапии
}

\author{
Лацин Цевертас ${ }^{1}$, Акдис Мубацел² \\ ${ }^{1}$ Институт медицинских наук, Университет Бурса Улудаг, Бурса, Турция \\ ${ }^{2}$ Швейцарский институт исследований аллергии и астмы, Цюрихский университет, Давос, Швейцария
}

\begin{abstract}
Аллергенспецифическая иммунотерапия (АСИТ) широко используется с целью обеспечения адекватного иммунного ответа, и в настоящее время это единственный вид терапии, модифицирующий патологический процесс. Существуют различные способы введения аллергена, включая подкожно, сублингвально, внутрилимфатически, накожно, интрадермально, перорально и интраназально. Несмотря на то, что оптимальный путь введения зависит от типа аллергена, некоторые пациенты остаются невосприимчивыми, и поэтому важно прогнозировать результат до и во время лечения. Следовательно, существует необходимость в выявлении потенциальных прогностических маркеров для иммунотерапии аллергенами. В обзоре обсуждаются резулбтаты современных исследований молекулярных механизмов АСИТ.
\end{abstract}

Ключевые слова: аллергенспецифическая иммунотерапия (АИТ), аллерген, подкожно, сублингвально, внутрилимфатически, накожно, интрадермально, перорально, интраназально, прогностические маркеры

Ответственный за переписку: Акдис Мубацел - профессор, Научно-исследовательский институт по аллергии и астме, Герман — Бурхард штрассе 9, СH-7265, Давос, Швейцария; E-mail: akdism@siaf.uzh.ch

ORCID ID: 0000-0003-2113-1870

\section{Авторы заявляют об отсутствии конфликта интересов.}

Финансирование

Исследование поддержано грантом Швейцарского национального научного фонда № 310030-179428, Центром астмы и аллергии им. Шона Паркера, Стэнфордского университета, США.

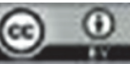

(C) Лацин Цевертас, Акдис Мубацел, 2019

This work is licensed under a Creative Commons Attribution 4.0 International License

Поступила 05.09.2019

Принята 15.09.2019 